\title{
LOS SEFARDÍES: ESPAÑOLES SIN PATRIA Y SU LENGUA
}

\section{INTRODUCCION}

Dos tendencias bien definidas dividen a los israelitas del mundo entero, clasificados en sefardíes y ashkenazíes. Las estadísticas dicen que en 1975 había en el mundo unos 13989650 de judíos más o menos. Antes de la segunda guerra mundial unos 16 millones de judíos se hallaban diseminados sobre la faz de la tierra. Más de cuatro millones de ellos vivían en Polonia y otros tantos en Rusia, en Hungría, en los Estados Unidos de América; algunos grupos menores vivían en las costas europeas, africanas, y asiáticas del Mediterráneo, así como también en la República Argentina y otros países de América Latina.

Desde hace más de mil años los judíos se han diferenciado entre sí en ashkenazíes y sefardíes, habiendo tomado estos nombres de la Biblia'.

¿Qué significa exactamente esta palabra sefardí, y cuál es su origen? Muchas son las interpretaciones que se han dado a este topónimo. Me voy a limitar a un simple resumen de las teorías explicadas por algunas autoridades ${ }^{2}$.

El nombre de Sefarad, con que designaban los hebreos desde tiempos antiguos a España, aparece por primera y última vez en la Biblia, en el libro de Abdías (I, 20), en el texto que dice: “y los desterrados de Jerusalem que en Sefarad [España] heredarán las ciudades de la tierra del mediodía"s.

${ }^{1}$ El ashkenazí es el judío de la Europa Oriental, de Rusia, y de Polonia, Lituania, etc. El sefardí es el judío mediterráneo, español, belga, norafricano, balcánico, etc.

${ }^{2}$ Dos distinguidos escritores, Abraham L. Laredo y David Gonzalo Maeso, publicaron en 1944, importantes estudios con el título "El nombre de Sefarad", Sef, 4 (1944), 349-363.

${ }^{8}$ A título de curiosidad reproduzco aquí el texto judeoespañol que he tomado de un libro publicado en judeoespañol en 1905: "Y los Kativos de este 
El primero que tradujo el nombre de Sefarad, por España, fue Jonatan ben Uziel considerado por los sabios de su época y los posteriores, como un verdadero maestro en la interpretación de las escrituras sagradas.

El célebre filólogo y poeta granadino Moisés ibn Ezra, al tratar de la historia del establecimiento de los judíos en la Península ibérica, dice que la mención de "Sefarad" que hace Abdías, se refiere a España. Y el famoso rabino y hombre de estado español de fines del siglo XV, don Ishaq Abrabanel, en su comentario al libro de Abdías concluye que la cautividad de Jerusalén en Sefarad estaba integrada por los hijos de Judá que habían sido deportados a España cuando la destrucción del primer templo y que se habían establecido en Lucena y Toledo. Por lo tanto, debido a estas definiciones, resulta que sefardí, signifique todo aquello que por su ascendencia genealógica y ritos, se relaciona con los judíos de España y Portugal, después de los edictos de 1492 y 1497.

La palabra ashkenazí viene de Ashkenaz, palabra que leemos también en la Biblia (Génesis, X, 3), que en la Edad Media se aplicó a Alemania. Los ashkenazíes por lo general hablan el yiddish, y diferencian también algunas partes del ritual.

Hasta la Edad Media, no parece haberse hecho en ninguna parte mención de ashkenazíes o de sefardíes. El historiador francés, Theodore Reinach, autor de Histoire des Juifs, nos asegura que fue en el siglo XVI, después de la expulsión de los judíos de España, que se comenzó a diferenciar entre los términos ashkenazi y sefardi.

\section{LOS SEFARDÍES}

La palabra sefardí que, como hemos visto, en hebreo significa ibérico, español, no es del todo desconocida por españoles e hispanoamericanos. Quiéranlo o no, los sefardíes pertenecen a la gran familia latina y son unos españoles más. El profesor Germán Arciniegas escribía en 1958 en El Tiempo, de Bogotá, Colombia, que los sefardíes: “. . .hacen parte de la provincia erran-

fonsado de los ižos de Israel eredaran lo ke es de los Kananeos asta Tzarfat; y los kativos de Yerushalayim, ke estan en Sefarad, eredaran las sivdades del Sud". (Cf. Sefer Tora Neviim. El libro de la ley, los prafetas, y las eskrituras, trazladado en la lingua espanyola. Parte segunda. Konstantinopla, 1905, Kapitulo sovre Ovadia, p. 247, verso 20). El título aquí mencionado es una transcripción del original ladino, o judeoespañol impreso en caracteres hebraicos cuadrados. 
te de España, que España, nación peregrina, tiene una provincia andante, una provincia sin tierra, la provincia hebrea de una tradición tan honda, trágica, humana y poética, como pueden serlo Castilla, Galicia o Andalucía".

$Y$ el Dr. José Vasconselos afirmaba en el año 1930 que los judíos españoles del Cercano Oriente son los lejanos parientes espirituales y la rama estimable y fiel a nuestra familia lingüística.

Lo más característico es que un sefardí, aun siendo natural de Salónica, Sofía, de Sarajevo, de Estambul, Marruecos o Esmirna, sigue siendo español. No conocerá el español del siglo XX, por ejemplo, pero sí conoce a la España antigua, y por consiguiente se puede justificar, hasta cierto punto, su amor a la tierra en que sus mayores tuvieron su siglo de oro y su esplendor. En 1927, un sefardí importante, residente de Marruecos, pronunciaba estas palabras que me permito reproducir aquí para mostrar que estos correligionarios sienten especial predilección por España. He aquí parte de este discurso:

Somos aquí españoles en todo, en nuestros gustos, impresiones, exaltaciones y sentimientos. Somos españoles por vocación, por temperamento y por simpatías; en nuestras venas circula sangre española; pensamos en español y sentimos de igual modo; algunas de nuestras oraciones las hacemos en español... España es nuestra patria, es la tierra bendita donde descansan los restos de nuestros antepasados, y natural es que sintamos por ella cariño y veneración...

Recuerdo también las palabras de unos de mis maestros sefardíes, en Salónica (donde yo nací) que, al terminar su conferencia en el Ateneo de Madrid, el 2 de diciembre de 1916, dijo: "Españoles fuimos, españoles somos y españoles seremos".

El sefardí no solamente ha heredado la lengua, las tradiciones y la música de España, sino también todos los defectos como todas las virtudes que caracterizan a los españoles. Es por esto que su amor por aquella tierra es todavía tan acentuado y espontáneo, que a pesar de los 488 años que han transcurrido desde la expulsión, conserva el folklore, la lengua (que llamaron ladino o judeo-español), las costumbres, las tradiciones y el recuerdo de la patria de sus antepasados. Una ausencia de más de cuatro siglos no los ha curado todavía del "mal de España".

Los judíos españoles tuvieron que desparramarse por el mundo. Se fueron a Francia, a Italia, el norte de África, Turquía,

${ }^{4}$ ISAAC ALtCheH y SAPORTA, Los españoles sin patria de Salónica. Madrid, 1917, p. 59. 
Asia Menor, Holanda, Inglaterra y otras partes. Se llevaron consigo la gran cultura hispanohebraica y una fuerte dosis de melancolía que los siglos no han logrado disipar de su austero carácter. Asombroso es, en realidad, que cientos de años después, siglos de aislamiento con la madre patria, se conserve relativamente tan pura la lengua de España, como a la espera de un resurgimiento. No le mintió al Dr. Ángel Pulido el que dijo: "Nosotros israelitas españoles nos gustamos mucho cuando topamos ocasión de poder hablar nuestra lengua"'5.

Ninguna familia olvida su prosapia española; en ello ponen la poesía y la honra del hogar. Casi todos, especialmente los inmigrantes de hace unos sesenta años, más o menos, saben bien de dónde vinieron sus abuelos, si de Granada, si de Sevilla, Barcelona o Portugal. Hasta pronuncian el castellano de una u otra manera según de donde vinieron. Esto lo comprobó hace varios años en un estudio muy interesante acerca del dialecto judeoespañol, que se habla en Nueva York, el hispanista norteamericano, el fallecido Max A. Luria que fue profesor de Brooklyn College, en Nueva York, durante muchos años ${ }^{6}$.

\section{LADINO O JUDEOESPAÑOL}

Lamento no poder esbozar aquí el problema lingüístico de los sefardíes. No me toca a mí escribir la historia del judeoespañol, o ladino, ni tampoco me creo capacitado para hacerlo. No soy filólogo ni pretendo ser perito en cuestiones de filología. Insignes filólogos han contribuido con sus estudios y observaciones a que no se perdieran por completo los tesoros folklóricos y lingüísticos de los judíos españoles. En mi modesta Bibliografía sobre el judeo-español que apareció en 1952 en el Bulletin Hispanique indiqué un gran número de estudios y artículos de carácter filológico y general sobre el tema.

Desde entonces para acá el interés ha aumentado. Cada día que pasa notamos que estudiantes en varias universidades de los

\footnotetext{
5 "Casi no se puede creer que los descendientes de los expulsados de España hace varios siglos sigan conservando por ella un amor tan profundo y desinteresado. Conservaron, entre otras cosas, el idioma que sacaron de España, mucho más valioso para ellos. . . sometidos a otras soberanías, víctimas de "pogroms" y persecuciones sin fin siguieron hablando nuestro idioma en familia, e incluso en sus transacciones comerciales.. " Cf. $A B C$, Madrid, Abril de 1965.

${ }^{6}$ MAX A. LURIA, Judeo-Spanish dialects in New York City. Todd Memorial Volumes. Philological studies, New York, 1930, t. 1, pp.7-16.
} 
Estados Unidos de América, y otras partes del mundo, vienen interesándose por el judeoespañol, y están preparando su tesis de maestría o de doctorado sobre algún aspecto del idioma, del folklore, de los romances, o la historia de los sefardíes en muchas partes del mundo.

Me parece importante aclarar de paso que las definiciones que he recogido acerca del judeoespañol son muchas y varias, a la vez que interesantes y contradictorias. Algunos creen que el judeoespañol es un ersatz ridículo del latín, un idioma bastardo, un patois bárbaro extraño a la civilización, una jerga bastardeada. A este dialecto se le ha llamado indistintamente ladino, ğudezmo, djidió, romance, espaniolit, sefardí, Hakitía, lingua franca, žargon, español. No voy a tratar de estas definiciones, en este estudio. Sin embargo, quiero aclarar que el término ladino está reservado para la lengua usada en las tradiciones de la Biblia y la literatura religiosa, y el de judeoespañol para la lengua corriente y familiar ${ }^{7}$.

Claro está que después de casi cinco siglos, se encuentran en el judeoespañol giros idiomáticos que se han perdido ya en el castellano de España e Hispanoamérica. Es importante recordar que a partir de los primeros años del siglo XVII, al cesar la corriente de exiliados marranos, se rompe todo contacto con España y las comunidades sefardíes. En la Exposición bibliográfica serfardi mundial que tuvo lugar en la Biblioteca Nacional de Madrid, el 18 de noviembre de 1959, el Ministro de Educación Nacional, señor doctor Jesús Rubio, señala en su discurso que “. . . ha ocurrido con el castellano de los sefardíes algo parecido a lo de aquella leyenda del trovador que al marchar a la guerra dejó su voz encantada en un rosal para que su amada pudiera seguir escuchándola.

${ }^{7}$ En el Congreso de Instituciones Hispánicas que tuvo lugar en Madrid en 1963, se creó La Comisión $F$. encargada por la Secretaría del Congreso del estudio de los problemas relativos al judeoespañol. Esta Comisión que estaba formada por don Federico Pérez Castro (Presidente), don Michael Molho (Vice-Presidente), don Francisco Cantera Burgos, Fernando Diaz Esteban, don Henry V. Besso, don Jesús Cantera y el relator, don Jacobo M. Hassan, decidió que: "Para deshacer la actual anarquía de la terminología en los estudios de distintos investigadores, la Comisión recomendó el uso en lo sucesivo de los términos "judeoespañol" para designar a la lengua, y "sefardî" a los judíos de origen español, quedando reservado el término "ladino" para el español empleado en las traducciones de la Biblia y libros de carácter religioso". (Conclusiones de la Comisión F. Congreso de Instituciones Hispánicas, en Presente y futuro de la lengua española. Actas del I. Congreso de Instituciones Hispánicas. Madrid, Ediciones Cultura Hispánica, 1964, vol. 2, pp. 428-430). 
Así los españoles de hoy podemos saborear, nostálgicamente, el castellano del siglo $X V$, encantado históricamente en la rama judía que un día se desgajó del tronco hispánico. .."

En efecto, la nota típica en este caso es el arcaísmo, al decir de Máximo José Kahn. Hasta los neologismos en este judeoespañol son derivaciones arcaicas ${ }^{8}$. Los sefardíes, siempre y por todo miran al pasado. Esto se ve en su.propia escritura. Cuando salieron de España empleaban caracteres latinos y escribían el castellano, como era justo, de izquierda a derecha, pero en los países Balcánicos lo empezaron a escribir de derecha a izquierda y con caracteres rabínicos.

Esto nos hace pensar en los hermosos versos de Longfellow al cementerio judio de Newport, traducidos de mano maestra por el poeta argentino, Héctor Pedro Blomberg:

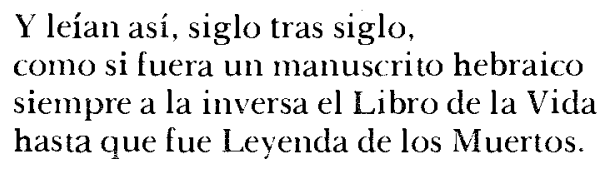

\section{ORIGEN DEL JUDEOESPANOL}

Es de suponer que los primeros monumentos lingüísticos del judeoespañol, daten del siglo XIII o XIV. "La parte principal de esa lengua es el español preclăsico o precolombino". 1492, año de la expulsión de los judíos de España, es también el año en que Colón descubrió América. El español que fue llevado al Nuevo Mundo por los conquistadores españoles debe de haber sido por consiguiente la misma lengua que los judíos se llevaron consigo al Oriente 9 . El profesor Max $\AA$. Luria afirma que los dialectos judeoespañoles de los Balcanes muestran una relación bastante estrecha con el español de los siglos XII y XIII. Y refïriéndose mấs especialmente al judeoespañol de Monastir (Yugoslavia), el profesor Luria nota que es el dialecto que se hablaba en la provincia de León hace más de 600 años ${ }^{10}$. El profesor Luria estuvo fascinado con el hablar de los judíos sefardíes de Monastir, acerca de los cuales preparó su tesis doctoral en 1930. Cuando visitó Monastir en 1927, el profesor Luria hizo grabar unos 26 discos del

${ }^{8}$ MÁximo JosÉ KAHN. "Salônica sefardita: el lenguaje", Hora de Españana, 17 (1938), pp. 25-41.

${ }_{9}^{9}$ LEO SPITZER, "The origin of the Judeo-Romance languages", Judaica, Buenos Aires, 12 (1944), p. 182.

${ }^{10}$ MAX A. LURIA. The Monastir dialect of Judeo-Spanish based on oral material collected in Monastir, Yugoslavia. Paris, 1930. 
habla de los sefardíes de esa ciudad como una evidencia viva del español del siglo XV. Indudablemente estos discos tienen una importancia filológica extraordinaria. Yo traté de conseguir uno o más de estos discos, pero a pesar de la buena voluntad del profesor Luria de querer prestármelos, no me fue posible hacer una cinta magnetofónica de estos discos. Parece que los discos en cuestión se hicieron en Europa con un aparato muy especial que fue difícil conseguir en los Estados Unidos, en aquel entonces"

Por su parte el joven profesor que fuera de Sarajevo (Bosnia), el Sr. Kalmi Baruch, que se educó en la Universidad de Viena, en su artículo acerca de "La lengua de los sefardim", habla del origen de la lengua española entre los sefardíes, y dice lo siguiente:

Sería difícil de determinar la época cuando el español se hizo lengua común de los judíos de España. Pero hay dicientes que al corriente del siglo XIII ya lo fué. Esto es tanto más probable cuando se toma en consideración que en este tiempo el idioma castellano ya abía alcanzado un alto grado en su desarrollo importancia social-política, la cual sin dubio fué una consegüencia de la victoria de los españoles sobre la historia literaria española de aquel tiempo por ver como fué la viva participación de los judíos en este campo de la vida espiritual...12

IV. Pronunciación del judeoespañol

Las principales peculiaridades fonéticas que se notan en el español de los sefardíes se discutieron ya en los trabajos de los especialistas: Wagner, Subak, Simon, Lamouche, Yahuda, Benoliel, Bénichou, Luria, y otros. Y según estos mismos especialistas, la pronunciación de los sefardíes se parece mucho al catalán, al asturiano, al gallego, al portugués, al leonés, y, en fin, al castellano.

Claro está que existen ciertas diferencias de pronunciación aun entre los mismos sefardíes. No tienen la misma pronun.

${ }^{11}$ Después de haberse jubilado del Brooklyn College, donde fue profesor de español durante muchos años, el profesor Max A. Luria falleció en marzo de 1966 a la edad de 74 años. En 1954 en calidad de Fullbright Scholar, el profesor Luria estuvo en Atenas, Grecia, y se jubiló en 1959. Con referencia a los discos que hiciera grabar en Monastir, cuando estaba estudiando el judeoespañol de este pueblo, la Sra. Edna de Luria tuvo la bondad de escribirme en mayo de 1970 acerca de estos discos. Me permito citar unas líneas de esta carta que está en inglés: "... If there is no record of a set of these recordings in the possession of the Smithsonian Institute, then mine must be the only one extant. . At any rate, my aim is to see that the material is made available to scholars in the field".

${ }^{12}$ Cf. Kalmi Baruch, "La lengua de los sefardim", ElMundo Sefardi, (Viena), 1 (1923), pp. 20-25. 
ciación en Salónica, en Esmirna, en Constantinopla, o en Bulgaria. Los sefardíes de Esmirna dicen, por ejemplo, que los de Salónica tienen un "cantito" al hablar. Sabido es que hay muchos pueblos que cantan al hablar, y entre los españoles, ciertas autoridades mencionan a los gallegos y los andaluces. Lo mismo diría el mexicano de los argentinos, y los dos con igual razón. No habla neutra, declaró Alfonso Reyes en un artículo titulado "Aduana lingüística". "Todos cantamos", dice, "pero ya sólo sentimos la canción extraña y no la nuestra que se nos borra como un perfume habitual..." Es lo de la paja y la viga en el ojo - oímos la tonada en la voz ajena y no la sinfonía en la propia.

Como a Salónica llegaron algunas familias de Italia y de Provenza, trajeron palabras que en Esmirna y en otras juderías son completamente desconocidas. Si en Salónica decían ascender, en Esmirna empleaban la palabra correcta encender. En Salónica decían favlar mientras que en Esmirna era hablar.

La profesora Dena Levy de Lida, de Brandeis University, en su tesis El sefardí de Nueva York que presentara en Columbia University en 1944, dice lo siguiente con referencia a estas diferencias de pronunciación entre los sefardíes de Salónica y los de Esmirna:

El grupo de Esmirna tiene la pretensión probablemente infundada de que el español que él habla es de cualidad superior al que hablan los Saioniclís, los Monastirlís, los Castorialís y los demás grupos de análoga procedencia. Con la opinión rutinaria que es corriente entre unos grupos y otros, los izmirlíes se ríen del modo de hablar de los de Salónica. Se burlan de su habla, mucho más lenta que la speya, y del alargamiento de las vocales acentuadas, que son rasgos característicos del dialecto de Salónica. Además de criticar el modo de hablar de la gente sefardí de dicha ciudad, censuran el lenguaje de otros grupos judeoespañoles que conocen. Creen que el dialecto de Monastir y el de Castoría son macho más rústicos que el suyo ${ }^{13}$.

Por su parte, el profesor Federico de Onís mantenía que el español de la gente de las aldeas en España se pronuncia del mismo modo que entre los sefardíes. En una conferencia dictada en diciembre de 1937 en el salón de la Hermandad Sefardita de América en Nueva York, el distinguido profesor dijo: “. . Cuando viajó por España y vivió con la gente de las aldeas, y entre ellos todavía se pronuncia el español del mismo modo que entre los sefarditas. Las palabras 'casa', 'mujer', 'navaja', entre los p. 7).

${ }^{13}$ DENA LEVY, El sefardí de New York, (tesis, Columbia University, 1944, 
campesinos de la Sierra de Gata en la provincia de Salamanca, se pronuncian del mismo modo que entre los judíos españoles de ahora. También por su tierra (en el corazón de España donde nació - Salamanca - ) oyó cantar a los españoles del campo con las mismas melodías los inolvidables romances que entonan los sefardim de los países del Mediterráneo"í.

A pesar de estas "pequeñas"diferencias, creo que podríamos apoyar la opinión de muchos especialistas que el judeoespañol hablado hasta el día de hoy no es siempre tan arcaico como se cree y tiene mucho del castellano moderno.

\section{LENGUA ESCRITA}

El judeoespañol se escribe en estos caracteres cursivos hebraicos que habían estado en uso en todas las comunidades de los países ibéricos desde hacía varios siglos. Constituye, en la práctica por lo menos, una especie de criptografía poco accesible a los no judios. Los sefardíes de entonces raras veces se servían de la escritura latina, debido a que la casi totalidad de sus relaciones eran judías.

Además del tipo rashío de los caracteres rabínicos cuadrados de que se servían para imprimir tanto los libros como los periódicos, los sefardíes usaban también otra ortografía especial llamada en ciertas partes de los Balcanes "el solitreo". El solitreo era una de las asignaturas que se enseñaban en las escuelas de Turquía a los muchachos sefardies. Se utilizaba también en los negocios y en la correspondencia de cada día con los agentes o representantes comerciales en el extranjero. Todos los libros de contabilidad se llevaban en esta clase de escritura ladina, o solitreo. Hoy día se usa más el abecedario latino.

\section{Corrupción del JudeoEspañol}

Se ha hablado de la corrupción que existe en el habla de los sefardíes. Claro está que algunas de estas corrupciones, que son lógicas, se notan en el judeoespañol. Pero deberíamos preguntarnos, como me he preguntado varias veces cuando vivía en Nueva York, si el judeoespañol que no ha tenido ningún contacto con España desde hace siglos, tiene más corrupciones que el

${ }^{14}$ FEDERICO DE ONÍs, España en América. Estudios, ensayos y discursos sobre temas españoles e hispanoamericanos, San Juan, Puerto Rico, 1955, pp. 104-105. 
español que hablan algunos hispanos de Nueva York, por ejemplo. Sabido es que el inglés ha influido enormemente en el hablar hispano de Nueva York, y esto a pesar de que los miles de hispanoamericanos no están aislados, tienen contacto continuo con su país de origen, tienen su prensa en castellano, sus escritores, y una literatura bastante rica escrita en castellano que leen diariamente. Los sefardíes, por el contrario, no han tenido esta oportunidad. Lo que deberían recordar algunas personas, que hablan desdeñosamente del habla de los judíos españoles, dice Rodolfo Gil, "no es la corrupción de sus locuciones ni la adopción de voces exóticas; lo más importante es recordar que esta lengua armoniosa y bendita que del solar castellano recogieron, y como reliquia de la perdida tierra de promisión llevaron en los entresijos de sus más caros amores, no se haya ido perdiendo hasta desaparecer totalmente de sus labios y de su recuerdo, a lo lar. go de su éxodo implacable y sin término...'15

\section{ViI. Conservación y decadencia del. judeoespañol.}

Sería bastante largo elaborar en este estudio las razones que ayudaron tanto a la conservación como a la decadencia del judeoespañol a través de los siglos. Como he indicado en otra parte, este dialecto se mantuvo relativamente limpio hasta hace unos setenta años, más o menos. Hoy se está corrompiendo demasiado, es verdad, y está en trance de perderse.

Veamos primero, a vuelo de pájaro, cómo ha sido posible este milagro de conservación. Tal es la pregunta antigua y siempre nueva ante el hecho del español de los judíos. En un último análisis, dice el profesor Ramos Gil, aparte del espíritu ultra conservador del pueblo judío, el hecho no tiene otra explicaciọn que la de un hondo amor a la tradición y a la patria de otros tiempos, idealizada ahora por el espejismo de la lejanía ${ }^{16}$.

Hace mucho tiempo que los sefardíes llaman la atención de los viajeros españoles. Unos setenta años después de la expulsión de 1492, Gonzalo de Illescas, en su Historia pontifical (Barcelona, 1606), afirmaba: “. . .y yo conocí en Venecia hartos judíos de Salónica que hablaban el castellano con ser bien mozos, tan bien, o mejor que yo". Estamos seguros que Gonzalo de Illescas se extrañaría si viera que después de casi cinco siglos, estos sefardíes

${ }^{15}$ RoDOlFo GIL, Romancero judeo-español, Madrid, 1911, p. 9.

${ }^{16} \mathrm{C}$. RAMos-GIL, La lengua española en Israel. Tesoro de los judios sefardies, Jerusalem, 1959, t. 1, pp. XXXI1-L: 
siguen hablando español y conservan las tradiciones que llevaron de España en 1492, tanto en los Balcanes, como en el Estado de Israel, en los Estados Unidos de América, en los países de Hispanoamérica y otras partes.

A pesar del olvido y la indiferencia de la madre patria, los sefardíes llevaron con ellos a los Balcanes y a otras parte no solamente la lengua española sino también la liturgia, el rito y todas las Sagradas Escrituras que habían sido traducidas en lengua castellana unos siglos antes de la expulsión. Y durante varios siglos, en todo el Imperio Otomano, los niños sefardíes recibían una educación que estaba basada en su mayor parte en los textos bíblicos transcritos en un castellano puro ${ }^{17}$.

Este idioma, el castellano, se perpetúa desde entonces, de generación en generación, sin ninguna alteración, ni desde el punto de vista fonético ni sintáctico, mientras que en la misma España y todas sus posesiones, el idioma sufría ciertas transformaciones.

Los sermones de los rabinos en la sinagoga contribuyeron, incluso más que la Biblia, a perpetuar la tradición de la lengua española. La Hagadá, o sea la narracción de la Pascua, las oraciones de Rosh Hashaná (Año Nuevo), la Ketubá de la Ley (Pentecostés), y la historia de Rut, las Máximas de los Padres de la Sinagoga, y machas otras oraciones no se leían más que en español.

Contrariamente al espíritu nacionalista que existía en varios países de Europa que obligaba a los sefardíes a cambiar su lenguaje familiar - el español - por el del país en que vivían, en el Imperio Otomano de antes de la primera guerra mundial, no pasó nada de esto. El gobierno otomano estaba fundado sobre la idea del estado religioso, que no consideraba la tierra y el lenguaje como fuerzas de unión. Admitía sólo la idea religiosa como base. Esta concepción o idea del gobierno explica, según el profesor Benardete, por qué en Turquía y en los países que salieron de la organización otomana, el judeoespañol persistió durante varios siglos. Esta falta de intercambio con las razas vecinas de la energía asimiladora, y que el "Apóstol" de los sefardíes, el Dr. Ángel Pulido compara "a los líquidos inmezclables y repelentes", hizo que los sefardíes pudieran mantener su lengua casi pura.

Las razones que dieron lugar a la decadencia del judeoespañol son también importantes y muchas, y requeriría más tiempo

${ }^{17}$ ABRAHAm GALANTÊ, "La langue espagnole en Oriente et ses déformations", Bulletin de l'Institut Egyptien.1 (1907), 15-23. 
para elaborarlas. Brevemente voy a citar algunas que, en mi opiniỏn, son las que contribuyeron en gran parte a este deterioro:

1. Las relaciones que existían todavía entre España y Oriente, durante los tiempos que siguen a la expulsión, fueron debilitándose poco a poco hasta llegar a extinguirse por completo.

2. La indiferencia del gobierno español que, durante largos períodos - y a pesar de las súplicas de hombres tan clarividentes como el Dr. Ángel Pulido y otros - no quiso hacer nada para ayudar a limpiar y pulir el judeoespañol18.

3. El judeoespañol no se acerca al castellano primitivo de una manera general porque se escribe, como se ha indicado antes, en caracteres hebraicos. El abandono del alfabeto latino y el uso de la escritura del tipo rashí adoptado para la transcripción del español, aislaron al judaísmo sefardí completamente del Occidente ${ }^{19}$.

4. La intolerancia y el nacionalismo en los países balcánicos que hace que el judeoespañol pierda terreno y deje de enseñarse en las escuelas. La asimilación se impone en Bulgaria, en Grecia, en Hungría, en Yugoslavia y hasta en la misma Turquía y en Francia, por no mencionar sino unos cuantos países.

5. La influencia del italiano y sobre todo el francés y otras lenguas extranjeras tales como el griego, el rumano, el búlgaro, etc., que transformaron hasta cierto punto la sintaxis, el léxico, las formas y aun la pronunciación. El influjo del francés se debe al establecimiento de las escuelas de la Alliance Israèlite Univer. selle.

${ }^{18}$ En la memoria leída en la Biblioteca Nacional de Madrid, en 1867, el Dr. Hartzenbusch, Director de la Biblioteca, se refiere a los sefardíes de Constantinopla en estas palabras: "Hay en la capital de Turquía y sus inmediaciones más de cuarenta mil judíos, que hablan todos una lengua importada de España, dialecto castellano, poco o nada conocido en nuestra península, en el cual tienen libros de devoción y de pasatiempo, y hojas volantes y periódicos de noticias de interés comercial, con artículos además de ense ñanza y de gusto... Ese idioma es el de muchos miles de hombres, entre los cuales hay personas de alguna instrucción, repartidos en Constantinopla, Salónica, Jerusalén y la costa de Berbería; conviniera que aprovechásemos esa favorable circunstancia para introducir libros nuestros en la Turquía europea y asiática, en Tánger y Marruecos . . . serían tal vez excelente medio para establecer relaciones con ventajas recíprocas, entre los españoles de hoy y los descendientes de otros que fuera de nuestra península conservan apellidos nuestros, y no poco del habla en que departieron con Juan Baena los capellanes de Isabel la Católica. Obligación de todo país cirnlizado es purificar y conservar su lengua donde quiera que se use" (Madrid, Imprenta y Estereotipia de M. Rivadeneyra, 1867, pp. 8-10).

19 JOSE NEHAMA, Histoire des Israélites de Salonique. Tome III. (L Age d'or du Séfaradisme Salonicien, (1536-1593). Deuxième fascicule. Salonique, 1936. 
6. El establecimiento de una prensa judeo-española a mediados del siglo XIX escrita en caracteres hebraicos, es otro motivo que contribuyó a la decadencia ${ }^{20}$. El profesor Abraham S. Yahuda, sabio sefardí, declaraba con razón que: "la prensa moderna judeoespañola y la literatura novelesca están tan afrancesadas que quizá sería más exacto llamarlas judeo-francesas que judeo-españolas"21.

7. El naciente nacionalismo en la Turquía de Kemal Ataturk, que impone a las minorías sefardíes el aprendizaje y uso de sus lenguas respectivas acorralando una vez más el hermoso lenguaje ladino a la intimidad de la familia, al dulce secreto del hogar.

8. Finalmente las bárbaras persecuciones, deportaciones y carnicerías que habían diezmado también la población sefardí de Salónica y otras partes de Grecia. Pero a pesar de estas restricciones, es en Salónica, última fortaleza del sefardismo tradicional, donde el judeoespañol se mantiene como lengua materna y hablada hasta la extinción de la comunidad judía en el año 1943. Y a pesar de muchos obstáculos, el judeo-español sobrevive en Turquía donde hay una población sefardí de unas 20000 almas. No ha perdido su gracia ni su pureza relativa. Se habla todavía el dialecto y se publican dos periódicos en judeoespañol impresos en caracteres latinos ${ }^{22}$.

Tanto en los Estados Unidos como en Israel hay todavía im. portantes comunidades de emigrantes sefardíes que aún conservan el habla familiar de sus mayores así como sus tradiciones.

\section{EL PORVENIR DEL JUDEOESPAÑOL EN LOS ESTADOS UNIDOS Y EN ISRAEL}

Quisiera rectificar aquí algunas aserciones mías hechas en 1948 respecto de la decadencia del judeoespañol en los Estados Unidos de América. En mi estudio Refranes judeoespañoles ${ }^{23}$,

${ }^{20}$ N. B. 'JoPson, "El estilo literario en judeo-español", Judaica, Buenos Aires, 7 (1939), 27-30.

${ }^{21}$ Cf. A. S. YAHUDA, Contribución al estudio del judeo español, RFE, 1915, pp.339-370.

${ }_{22}$ C. M. J. Benardete, Hispanic culture and character of the Sephardic Jews, New York, Hispanic Institute in the United States, 1953, pp. 121-122, y p. 132 , nota 2 .

${ }^{23}$ HENRY V. BESSO, "Judeo-Spanish proverbs. Their philosophy and their teaching", $B H i, 50$ (1948), 370-387. 
decía en una nota lo siguiente: “. . .que nos guste o no, el español que se habla entre los sefardies pierde terreno; la segunda generación de sefardíes en los Estados Unidos habla español muy mal, o no lo hablan del todo; son pocos los que verdaderamente han prestado atención y han intentado mejorar su conocimiento del idioma estudiando el castellano moderno"z4.

Las condiciones actuales no pueden corresponder, sin embargo, a las que me fue dado observar en otros tiempos. Las cosas y los tiempos han cambiado. En Nueva York, por ejemplo, el judeoespañol sigue su decadencia, es verdad; pero el sefardí moderniza, hasta cierto punto, su español en contacto con tantos millares de hispanohablantes de Cuba, de Puerto Rico, de México; en contacto con españoles de todas partes. En una entrevista realizada hace unos 20 años, con el profesor Ernesto Guerra Dacal (grabada en cinta magnetofónica), el profesor M. J. Benardete dijo estas palabras: “. . .Me parece a mí que el futuro del judeoespañol está en las·Áméricas; el sefardí de Nueva York moderniza su español en contacto con tantos millares de hispanos de todas partes. . .; y en los demás países de Hispanoamérica, el sefardí moderniza también su español, y no le cuesta trabajo volver a encontrar lo que ya sabía pero que parece que se había olvidado, y en muy breve tiempo está en condiciones de estar al día. (Por lo tanto), el futuro del judeoespañol está en Hispanoamérica, y no en ninguna otra parte"25.

Otro distinguido sefardí, el finado Sr. don Sam Levy, redactor en jefe que fue durante muchos años de La Época de Salónica, y de "Les Cahiers Séfardis" publicados en París después de la segunda guerra mundial, y un gran luchador en favor de la conservación del judeoespañol, resume este problema de esta manera:

1. "El judeoespañol, que ha desempeñado un gran papel en el pasado y que está a punto de desaparecer, al decir de muchos, está, al contrario, como el fénix, en vía de renacer de las cenizas.

24 JACK BEHAR, "La Idioma espanyola" (en judeoespañol), en: La Vara, New York, December 30, 1938, vol. XVII, núm. 18. En uno de los párrafos de este artículo, en judeoespañol, impreso en caracteres hebraicos cuadrados, el Dr. Behar dice: "La generasyon prezente sefardit konosemos la idyoma espanyola sin la necesidad de irmos a la eskola por embezarmola. Alora, esto es una okasion para kontinuar a ensenyar a nuestras kriaturas en kara sin kostarmos nada otro ke poko de buena voluntad".

${ }^{25}$ El Dr. Jack Behar que ejercía la medicina en Nueva York, en su artículo citado apoyaba la enseñanza del español a la juventud sefardí por la sola razón de que el Gobierno de los Estados Unidos "da una importansa capitala y costa de mui serka a los paizes latinos de la Amerika del Sud..." 
Esta vez en el Nuevo Mundo, donde el español se acerca mucho más a nuestro dialecto que el español de España".

2. "El español de Hispanoamérica tiene todavía la ventaja de unir en el mismo idioma a los sefardíes y ashkenazíes, cosa que ha sido rara en la Diáspora. Aún más: mientras que el yiddish en la América Hispánica, por lo menos, pierde terreno constantemente, el judeoespañol está ganando todos los días. La razón es simple, y se debe a que los ashkenazíes, dejando aparte su viejo idioma, el yiddish, se ven obligados a hablar el idioma de su nuevo país".

3. "Se sobreentiende, desde luego, que el hèbreo quedará siendo la lengua nacional del Estado de Israel, pero en la diáspora no podrá desempeñar más que un papel religioso limitado al culto y a la sinagoga, y los judíos no podrán hacer sino hablar la lengua del país donde viven".

En el Estado de Israel, donde viven unos 300000 sefardíes de habla española, el judeoespañol ha tenido una gran infiltración de giros y palabras extrañas; sin embargo, todavía se usa el idioma en las familias ${ }^{26}$.

Hasta hace unos pocos años la prensa judeoespañol en Israel contaba con dos publicaciones semanales: La Verdad y El Tiempo. Desde hace unos 25 años, creo, estos periódicos se publicaban en judeoespañol, no en caracteres hebraicos, sino en caracteres latinos, con una ortografía fonética llevada al último extremo. Una de estas publicaciones, El Tiempo, dejó de existir por varias razones ${ }^{27}$.

${ }^{26}$ Parece haber una confusión -o mejor dicho una exageración - en cuanto al número exacto (más o menos) de los judíos sefardíes en el Estado de Israel: 1) El Prof. C. Ramos-Gil, en su estudio sobre "La lengua española en Israel" afirma que: "Una buena parte de casi un millón de judios sefardies para los que el español es una habla familiar se halla activamente en israel..." (Cf. Tesoro de los Judios Sefardies, Jerusalem, 1959, vol. 1, p. XXXII). 2) El Dr. Blas Piñar López, hablando de su visita a Israel en marzo de 1962, dice: "Desde aquí debemos considerar que en Israel hay trescientas mil personas de habla española". (Cf. "Mi experiencia personal del mundo Sefardî", Actas del I. Simposio de estudios sefardies, Madrid, 1970, p. 187). Y por su parte, el Sr. don Isaac R. Molho, Director de la Revista Tesoro de los judios sefardíes, en una entrevista con el $A B C$, de Madrid, en junio 21 de 1961, contestando a la pregunta ¿"Cuántos sefardíes hay en Israel?" dijo: "En Israel, los sefardíes de habla española cuentan no más de unos 300000 . Algunos miles son nacidos en el pais, y otros en Grecia, Turquia, Bulgaria, Egipto, Marruecos, etc." En vista de estas informaciones autorizadas del Sr. Molho, creo que debiêramos considerar que la población de judios sefardíes, de habla española, en Israel, es de 300000 más o menos.

${ }^{27}$ El Director que fuera del periódico semanal "El Tiempo" de Tel-Aviv, Sr. Isaac Benrubí, lanzó “. . . una yamada a todos los ke escriven esta lingua, 
La Sección de Radio (Kol Israel - Voz de Israel) transmite diariamente unos programas en judeoespañol muy escuchados, lo que prueba que esta lengua sigue viviendo en los descendientes de los sefardíes. El finado Ytzhak Levy, director que fue del programa judeoespañol de Kol Israel trató de mejorar el idioma y "... .estaba asiendo un gran esforzo por desbarassar el idioma de los terminos turkos, o italianos o franseses, $i$ aserkar kuanto mas mutcho el linguaje del idioma castellano..."28

El porvenir del judeoespañol, que se conoce con el nombre de espaniolit, en Israel, posiblemente pueda perdurar unos pocos años más. Está perdiendo terreno desde hace unos 15-20 años, y sin duda, al decir del profesor C. Ramos Gil, desaparecerá o quedará reducido al mínimo ${ }^{29}$. Al incorporarse los restos dispersos de las comunidades sefardíes al moderno Estado de Israel, el ladino, idioma de por sí anacrónico, está a punto de capitular ante el hebreo, lengua oficial que se impone en las escuelas, y los occidentales: inglés, francés e italiano, más útiles y activos. Algunos de los problemas relacionados con la decadencia del judeoespañol en Israel, han sido discutidos por ciertas personalidades (sefardíes y españoles), en los últimos años. Me permito citar aquí la opinión del distinguido doctor don Blas Piñar López, director que fue del Instituto de Cultura Hispánica en Madrid. En un discurso presentado en una de las sesiones del Simposio Serfardí que tuvo lugar en Madrid, en 1964, el doctor Piñar López dijo: "En Marzo de 1962 acudí a Israel en compañía de mi esposa y de Don Francisco Cantera Burgos... y en aquel viaje pude percibir que a los peligros ya enunciados que amenazaban la cultura sefardí era necessario agregar otro: el esfuerzo de hebraización total acometido por el gobierno israeli... En este trance de hebraización el ladino (judeoespañol), o sea el castellano de las comunidades sefardíes, se halla en peligro de desaparecer... Por eso mismo es apasionante y exige de España y del mundo hispánico una actitud que no puede ser la de simple espectadora"so.

Por su parte, el profesor M. J. Benardete decía, en esa entrevista a que me refería antes ${ }^{31}$, que "El Estado de Israel como es-

para ke se organise una asamblea i se meta en freno en esta anarchia ke existe en la expresión i en la escritura". Ci. Lotns Bertrand, "El 'españolit' se castellaniza", Nuestra Tribuna, Bogotá, Colombia, núm. 60, junio de 1960.

\footnotetext{
${ }^{28}$ Cf. LOUIS BERTRAND, art. cit.

${ }^{29}$ C. C. RAINOS GIL, cit. supra, nota 16.

${ }^{30}$ BLAS PIÑAR LÓPEZ, art. cit, supra, nota 26.

31 Véase supra, nota 25.
} 
tado no tiene interés en el judeoespañol, pero el Estado de Israel tiene interés en mantener sus influencias y prestigio en toda la América Hispana. (Por lo tanto), hay una necesidad política de conservar el español, enseñar el español, entrenar a gente en el español para este propósito de mantener prestigio. Y como tienen a los sefardíes allí, ya preparados con su lengua, ésos - los sefardies - pueden ser los futuros embajadores, maestros, propagandistas de Israel en Hispanoamérica. El sefardí, concluye el profesor Benardete, tiene un papel asegurado en la política de Israel en la América Hispana".

Otro escritor y periodista sefardí, el difunto don Isaac R. Molho, director de la importante revista Tesoro de los judíos sefardies, establecido en Jerusalen unos 20 o 25 años antes del establecimiento del Estado de Israel, en 1948, decía: "El habla judeoespañola se perderá si España no hace lo necesario para conservarla e incitarla. Los sefardíes son gente importante. Los que proceden de los Balkanes, por ejemplo, ocupan los primeros puestos de la Banca, la industria, las finanzas y la Marina. Los dueños de los cinematógrafos más importantes de Tel Aviv y Haifa son judios sefardies" 32 .

Indudablemente, como ya lo hemos dicho en varias ocasiones, todos los sefardíes, sin excepción están unidos a España por atavismo, por la lengua, por la cultura. España debiera crear cursos de lengua castellana, en Israel, y en otras partes, bolsas de viaje para que los sefardíes、 (especialmente los estudiantes), puedan visitar España, enviar profesores a Israel, compañías tea * trales, músicos... y el comercio, fomentar las relaciones comerciales.

Volviendo al distinguido don Blas Piñar López, estas próxi* mas líneas tienen una importancia especial, y me permito citarlas: "Pensar que lo español ha sido algo sagrado para los sefardíes durante más de cuatrocientos años; que lo español, en gran medida, les ha salvado de la absorción por el medio, conservando su personalidad; y que ahora en Israel lo sefardí quede olvidado o reducido a una mera curiosidad erudita me parece un error lamentable; y no solamente como español, sino también desde el punto de vista israelí..."3s

Para terminar voy a presentarles unos versos que escribió poco antes de su muerte el Sr. Abraham Cappón, poeta y periodista sefardí y director del semanario judeoespañol La Alborada,

32 CARloS-LuIS AlVAREZ, "Los judíos sefardies están unidos a España, por el idioma, la cultura y la cocina", $A B C$, Madrid, junio 21 de 1961.

${ }^{33}$ Cf. BLAS PIÑAR LóPEZ, art. cit., p. 187. 
que se publicaba en Sarajevo, Yugoslavia. Conservo adrede el vocabulario del original para que se observe la relativa pureza del lenguaje. Se titula "A España", y dice:
A ti, España bien querida, nosotros "madre" te llamamos $y$, mientras toda nuestra vida tu dulce lengua no dejamos.
Aunque tú nos desterraste como madrastra del seno, no estancamos de amarte como santísimo terreno, en que dejaron nuestros padres a sus parientes enterrados y las cenizas de millares de tormentados y quemados. Por ti nosotros conservamos amor filial, país glorioso, por consiguiente te mandamos nuestro saludo caluroso ${ }^{34}$.

HENRY V. BESSO

Miami Beach, Fla.

${ }^{34}$ Este poema se publicó en La Vara, Nueva York, el $1^{\circ}$ de marzo de 1935, en Judeoespañol (en caracteres hebraicos cuadrados);y en Actas del l. Simposio de es. tudios sefardies, Madrid, 1970, p. 261. 